\title{
Dorsal Approach For Impacted Comminuted Distal Radius Fracture By Open Reduction And Internal Fixation By Plate And Screws With Bone Grafting
}

\author{
Mohamed Saad Abdel-Fattah Monged ${ }^{1, *}$ M.B.B.Ch; Ahmed Mohammed Badawy ${ }^{2}$ MD ;
} Ahmed Saied Mohammed ${ }^{2}$ MD

\section{*Corresponding Author: \\ Mohamed Saad Abdel-Fattah Monged sa17adm@gmail.com}

Received for publication February 13, 2021; Accepted March 31, 2021; Published online March 31, 2021.

Copyright 2020 The Authors published by Al-Azhar University, Faculty of Medicine, Cairo, Egypt. All rights reserved. This an openaccess article distributed under the legal terms, where it is permissible to download and share the work provided it is properly cited. The work cannot be changed in anyway or used commercially.

doi: 10.21608/aimj.2021.61357.1418

${ }^{1}$ Orthopedic Surgery Department, El-Mattaryah teaching hospital, Cairo , Egypt.

${ }^{2}$ Orthopedic Surgery Department, Faculty of Medicine, Al-Azhar University, Cairo , Egypt.

\section{ABSTRACT}

Background: The distal radius fracture is the most common fracture seen in an emergency, making up $17 \%$ of all fractures. It is complex to treat affected comminuted distal radius fracture. Especially when the fractures are dorsally comminuted, internal fixation via a dorsal approach should be considered.

Aim of work: To evaluate the results of dorsal plating in patients with impacted comminuted distal radius fracture.

Patient and Methods: This study was done at Al-Azhar University Hospitals, Air-Force military hospital \& El-Mattaryah teaching hospital, during the period of December 2019 and December 2020. 13 males and 7 females (20 fractures) aged 22 to 59 (mean 43.2) years underwent fixation of distal radius fracture by dorsal plating with bone grafting. The mode of trauma was high energy mechanism in 11 patients and low energy mechanism in 9 patients. Radiological and clinical outcomes was evaluated.

Results: In the outpatient clinic, twenty patients were followed up for evaluation of fracture healing, ROM, hand grip and return to work. The Modified Mayo Wrist Score was $72.5 \%$ after at least 6 months follow up. Conclusion: Dorsal plating with bone grafting for impacted distal radius with dorsal comminution allows accurate reduction and maintenance with early mobilization, good function and an early return to work.

Keywords: ORIF, Distal radius, Dorsal approach, Intra-articular, Bone grafting.

Disclosure: The authors have no financial interest to declare in relation to the content of this article. The Article Processing Charge was paid for by the authors.

Authorship: All authors have a substantial contribution to the article.

\section{INTRODUCTION}

The distal radius fracture is the most common fracture seen in an emergency, making up $17 \%$ of all fractures. ${ }^{1}$ In terms of the 3 -column model defined by Rikli and Regazzoni, it is useful to consider the distal forearm. ${ }^{2}$

The fundamental theory of fracture treatment is to achieve precise fracture reduction, which is the fundamental principle of fracture treatment, and then to use an immobilization procedure to sustain and maintain the reduction. There are a variety of treatment methods available to stop loss reduction in an unstable fracture of the distal end of the radius. ${ }^{3}$ Dorsal plating has several theoretic advantages. For most surgeons, it is technically familiar, and the technique eliminates neurovascular structures on the palmar side. The fixation is on the fracture's compression side and offers a collapse-proof buttress. Initial reports of the technique showed promising results with the theoretical benefits of earlier function return and better radial anatomy restoration than seen with external fixation. Dorsal plating has been associated with extensor tendon complications, but this complication is overcome by low profile plates. ${ }^{4}$

\section{PATIENTS AND METHODS}

Study design:

This is a prospective randomized controlled study that was conducted to evaluate the results of dorsal plating with bone grafting in patients with impacted comminuted distal radius fracture.

Study location (settings) and duration:

Orthopedic Department, Al-Azhar University hospitals, Cairo, Egypt.

Orthopedic Department, El-Mattaryah teaching hospital, Cairo, Egypt.

Orthopedic Department, Air-Force military hospital, Cairo, Egypt.

Between December 2019 and December 2020

Study subject:

20 patients suffering from impacted comminuted distal radius fracture including seven women and thirteen men were presented to Al-Hussien hospital, Sayed Galal hospital, El-Mattaryah teaching hospital \& Air-Force military hospital, M to F ratio was 1.8:1. 
The age of the patients was ranging from 22 to 59 years with a mean age of 43.2 years. The mechanisms of injury included high energy mechanism in eleven patients and low energy mechanism in nine patients. Dominant hand included in eleven patients and non-dominant in nine patients. Right side affected in eleven patients and left side in 9 patients.

Inclusion criteria:

Young and elder people (20-60) years old.

Both genders will be included.

Patients with dorsally impacted comminuted distal radius fracture.

Mode of trauma: including both low and high velocity injury.

AO C3-type fractures.

Exclusion criteria:

Patients with simple (Non-comminuted) distal radius fracture.

Patients with poor general and mental condition.

Patients refused to participate.

Pathological fractures.

Open fractures.

Methods:

The patients were examined clinically to exclude any vascular or neurological injuries, radiographs were obtained in the AP and Lat. Views and CT done, taking in consideration the above inclusive and exclusive criteria. Patients were put in the slab until the time of surgery.

Laboratory investigations include complete blood count, blood sugar, liver and kidney functions and coagulation profile to assess their general condition.

\section{Anesthesia:}

Fifteen patients underwent general anesthesia and five patients underwent supra-clavicular anesthesia and all were after the anesthesiologist team recommendations according to the general condition of the patients or the recommendations of the patients themselves.

Operative technique:

The procedure was conducted in supine position.

Limb resting over a side table and a well-padded pneumatic tourniquet placed around the upper arm.

Preparing and draping the limb in the usual sterile fashion, Iliac crest also included in the surgical field.

An 8-cm longitudinal incision that crosses the wrist joint halfway between the radial and ulnar styloids on the dorsal aspect of the wrist.

The subcutaneous fat incised in the same line with the skin incision to reveal the extensor retinaculum which covers the tendons in the six compartments on the posterior aspect of the wrist joint.

A dorsal exposure achieved through an interval between third and fourth extensor compartments.

Using self-retaining retractors or hand-held retractors to maximize field and for good visualization of the distal radius.

Elevating the periosteum \& flattening of Lister's tubercle.

Elevating the fracture fragments using freer elevator or dental probe. Traction or external fixation also important to facilitate fracture fragment reduction \& bone grafting. (Figure 1)

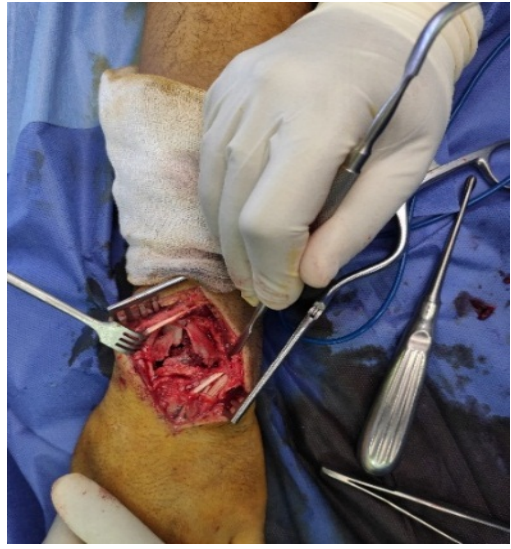

Fig. 1: Dorsal approach showing comminuted distal radius fracture during elevating fragments.

Using K-wires to achieve temporary stabilization of the fracture fragments. Contouring of the plate then fixation to the bone with screws, depending on the fracture pattern. (Figure 2).

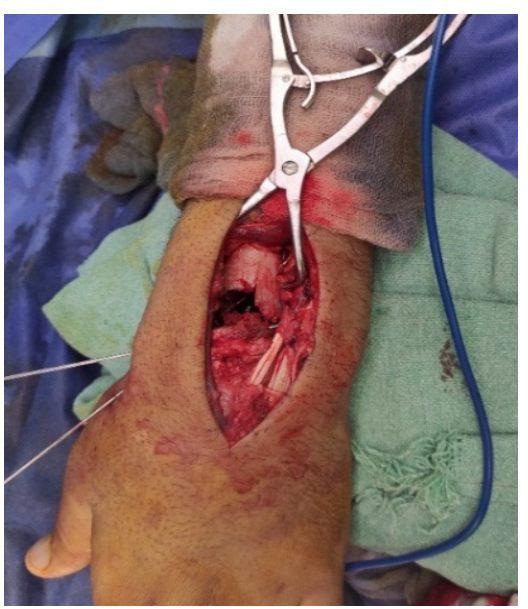

Fig. 2: Fixation of fragments with K-wires. Evaluation of reduction, plate and screw position and fracture stability during operation using fluoroscopic images

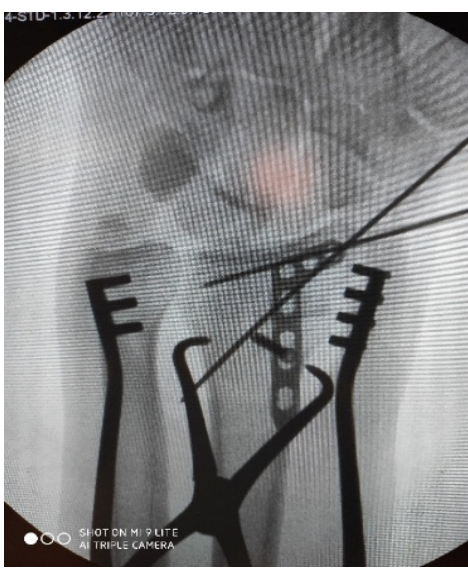

Fig. 3: Using image during fixation.

The second and forth compartment are sutured back underneath the EPL tendon without any tension.

Closure of subcutaneous layer.

Closure of the skin.

Post-operative care: 
A At the end of the situation, a well-padded gauze dressing is applied. A volar splint is applied to support wrist with the digits left free.

Post-operative X-rays were taken both in PA and Lateral views and fracture reduction was confirmed.

The patients received post-operative antibiotics.

Immediately post-operative, digital motion must be encouraged.

Elbow and shoulder mobilization exercises.

The patient had clinical radiological follow up each 2 weeks.

Splint removed after $4-6$ weeks according to union. Physiotherapy and rehabilitation started after removal of splint.

Evaluation:

All patients evaluated using the Modified Mayo Wrist Score (MMWS). The MMWS consists of 4 domains: pain, grip strength, range of motion, and return to work. Total score is 100 points, each domain represent 25 points. Good function is correlated with high scores: excellent function when the score above 90 and poor function when less than 65.5

Male pt. 22 years old, medically free, with left comminuted fracture distal end radius. (Figures $4,5,6,7)$
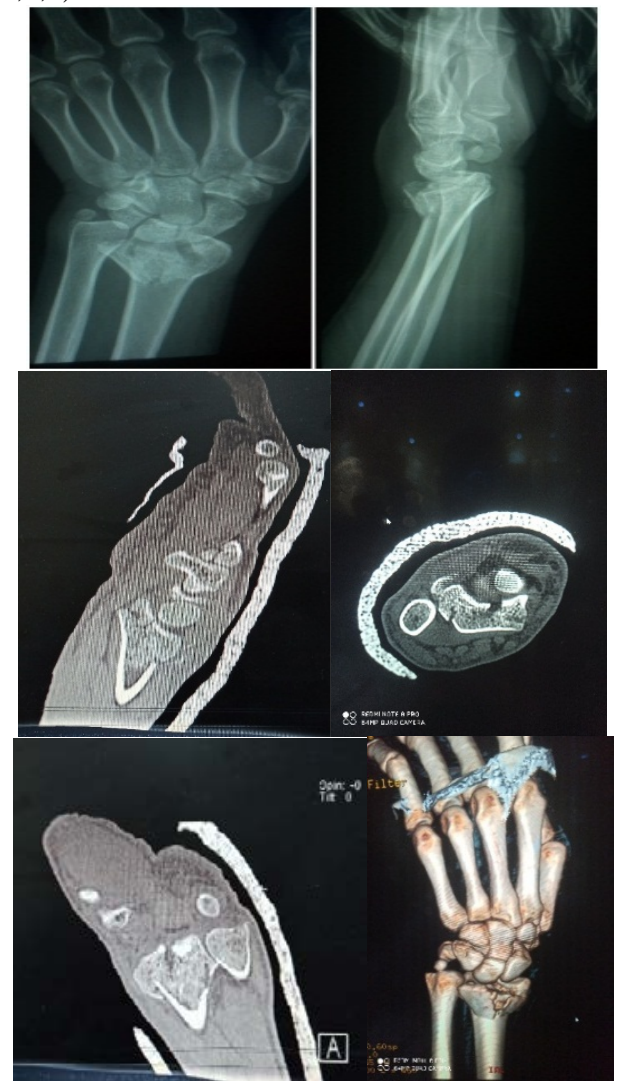

Fig.4: Pre-Op imaging (X-ray, CT \& 3D CT) .
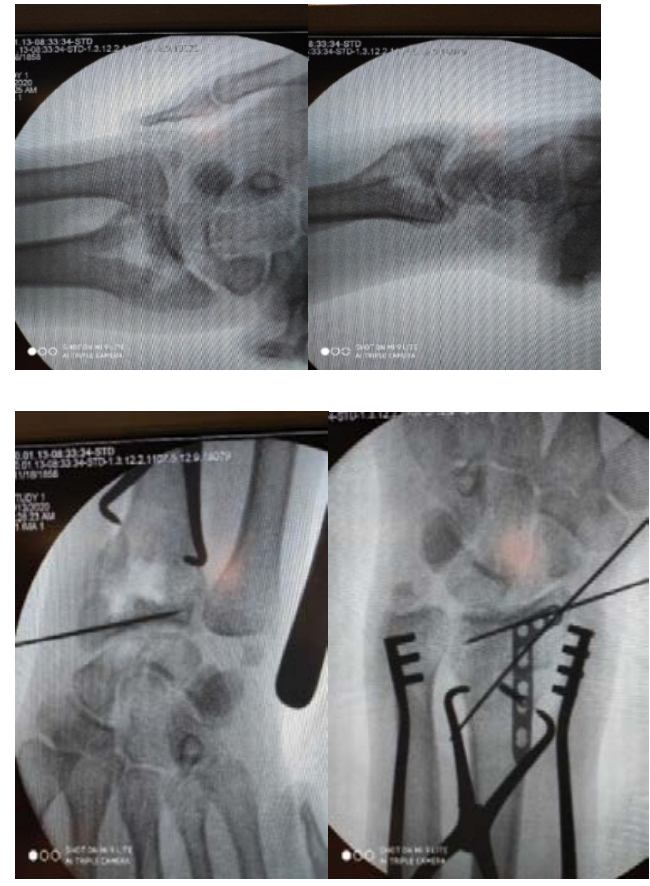

Fig. 5: Intra-Op imaging.

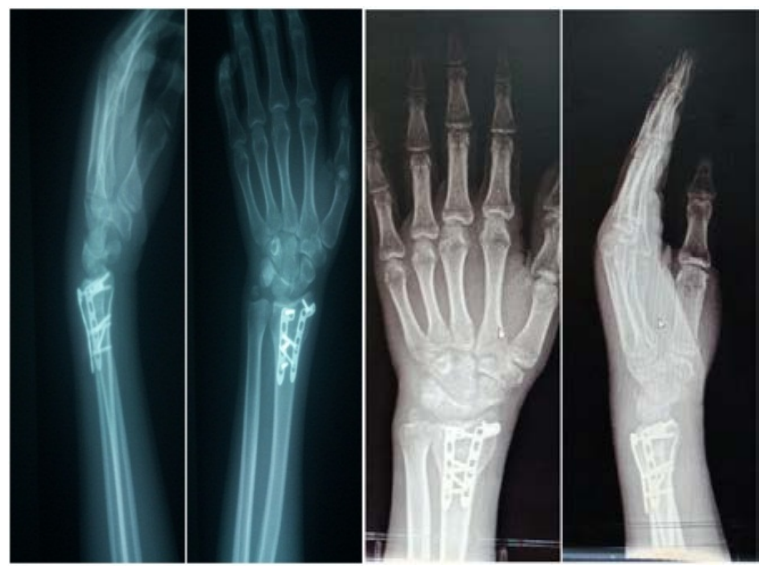

Fig. 6: Post-Op \& Follow up imaging.

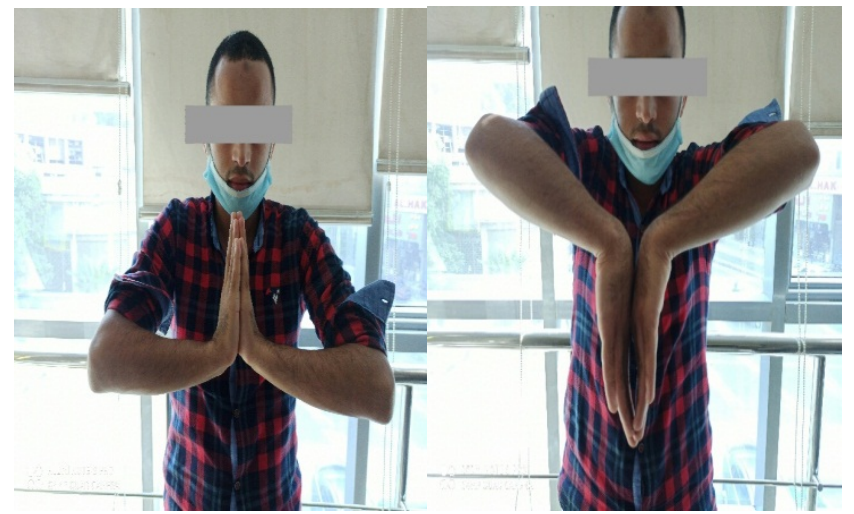

Fig. 7: Clinical assessment. 


\section{RESULTS}

\begin{tabular}{||r|r||r||}
\hline \multicolumn{2}{|c||}{} & $\begin{array}{r}\text { Studied patients } \\
\text { (N= 20) }\end{array}$ \\
\hline \hline \multirow{2}{*}{ Age (years) } & Mean \pm SD & $43.2 \pm 10.8$ \\
\cline { 2 - 2 } & Min - Max & $22-59$ \\
\hline
\end{tabular}

Table 1: Description of age in all studied patients.

This table shows the description of age in all studied patients. The mean age of all studied patients was $43.2 \pm 10.8$ years with minimum age of 22 years and maximum age of 59 years.

\begin{tabular}{||r|r|rr|}
\hline \multicolumn{2}{|c|}{} & $\begin{array}{r}\text { Studied patients } \\
\text { (N= 20) }\end{array}$ \\
\hline \multirow{2}{*}{ Sex } & Male & 13 & $65 \%$ \\
& Female & 7 & $35 \%$ \\
\hline
\end{tabular}

Table 2: Description0of sex in all studied patients.

This table shows the description of sex in all studied patients. There were 13 males (65\%) and 7 females (35\%) in all studied patients.

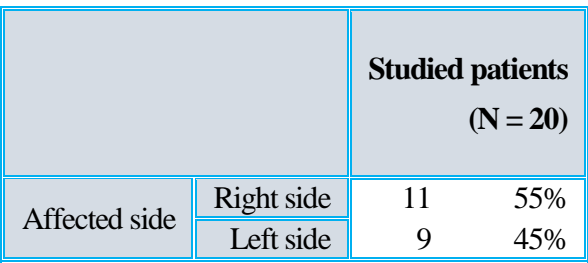

Table 4: Description of dominant side in all studied patients.

This table shows the description of dominant side in all studied patients. There were 11 patients (55\%) dominant side affected and 9 patients (45\%) non-dominant side affected in all studied patients.

\begin{tabular}{|c|c|c|c|}
\hline & Studi & $\begin{array}{l}\text { tients } \\
=20)\end{array}$ \\
\hline \multirow{2}{*}{ Mode of trauma } & High & 11 & $55 \%$ \\
\hline & Low & 9 & $45 \%$ \\
\hline
\end{tabular}

Table 5: Description of mode of trauma in all studied0patients.

This table shows the description of mode of trauma in all studied patients. There were 11 patients (55\%) with high trauma and 9 patients (45\%) with low trauma in all studied patients.

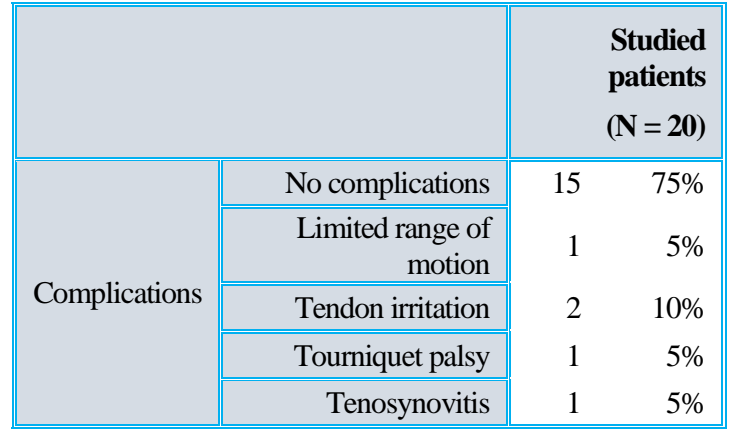

Table 6: Description of complications in all studied0patients.

This table shows the description of complications in all studied0patients. There were 2 patients (10\%) with Tendon irritation, 1 patient (5\%) with limited range of motion, 1 patient (5\%) with tourniquet palsy, 1 patient (5\%) with tenosynovitis while there were no complications in 15 patients $(75 \%)$.

\begin{tabular}{|c|c|c|c|c|c|c|c|}
\hline & & & $\begin{array}{l}\text { ative } \\
=20 \text { ) }\end{array}$ & & $\begin{array}{l}\text { Healthy } \\
(\mathrm{N}=20)\end{array}$ & $\mathbf{T}$ & P-value \\
\hline \multirow{2}{*}{ Flexion } & Mean & & 58.2 & & 70.0 & \multirow{2}{*}{5.25} & \multirow{2}{*}{$<0.001 \mathrm{HS}$} \\
\hline & $\pm \mathrm{SD}$ & & 7.7 & & 6.5 & & \\
\hline \multirow{2}{*}{ Extension } & Mean & & 53.3 & & 64.9 & \multirow{2}{*}{6.55} & \multirow{2}{*}{$<0.001 \mathrm{HS}$} \\
\hline & $\pm \mathrm{SD}$ & & 5.3 & & 5.9 & & \\
\hline \multirow{2}{*}{$\begin{array}{r}\text { Radial } \\
\text { deviation }\end{array}$} & Mean & & 15.1 & & 22.0 & \multirow{2}{*}{8.25} & \multirow{2}{*}{$<0.001 \mathrm{HS}$} \\
\hline & $\pm \mathrm{SD}$ & & 2.8 & & 2.5 & & \\
\hline \multirow{2}{*}{$\begin{array}{r}\text { Ulnar } \\
\text { deviation }\end{array}$} & Mean & & 25.0 & & 34.1 & \multirow{2}{*}{7.87} & \multirow{2}{*}{$<0.001 \mathrm{HS}$} \\
\hline & $\pm \mathrm{SD}$ & & 3.7 & & 3.6 & & \\
\hline \multirow{2}{*}{ Pronation } & Mean & & 76.1 & & 83.2 & \multirow{2}{*}{5.06} & \multirow{2}{*}{$<0.001 \mathrm{HS}$} \\
\hline & $\pm \mathrm{SD}$ & & 4.9 & & 4.0 & & \\
\hline \multirow{2}{*}{ Supination } & Mean & & 82.1 & & 95.0 & \multirow{2}{*}{15.2} & \multirow{2}{*}{$<0.001 \mathrm{HS}$} \\
\hline & $\pm \mathrm{SD}$ & & 2.3 & & 3.0 & & \\
\hline \multirow{2}{*}{ ROM } & Mean & & 19 & & 25 & \multirow{2}{*}{5.08} & \multirow{2}{*}{$<0.001$ HS } \\
\hline & $\pm \mathrm{SD}$ & & 5.3 & & 0.0 & & \\
\hline \multirow{4}{*}{ ROM } & 10 & 2 & $10 \%$ & 0 & $0 \%$ & \multirow{4}{*}{$\begin{array}{r}\mathrm{X} 2= \\
19.3\end{array}$} & \multirow{4}{*}{$<0.001 \mathrm{HS}$} \\
\hline & 15 & 7 & $35 \%$ & 0 & $0 \%$ & & \\
\hline & 20 & 4 & $20 \%$ & 0 & $0 \%$ & & \\
\hline & 25 & 7 & $35 \%$ & 20 & $100 \%$ & & \\
\hline
\end{tabular}

Table 7: Comparison between operative side \& healthy side as regard ROM.

T: independent sample T test. $\quad$ HS: p-value $<0.001$ is considered highly significant.

$\mathrm{X} 2$ : Chi-square test.

This table shows highly statistical significant difference (p-value $<0.001$ ) between studied groups as regard ROM (flexion, extension, radial 
deviation, ulnar deviation, pronation \& supination).

\begin{tabular}{|c|c|c|c|c|c|}
\hline & & $\begin{array}{r}\text { Operativ } \\
\text { e } \\
(\mathrm{N}=20)\end{array}$ & $\begin{array}{r}\text { Health } \\
y \\
(\mathbf{N}= \\
20)\end{array}$ & $\mathbf{T}$ & $\begin{array}{r}\text { P- } \\
\text { valu } \\
\text { e }\end{array}$ \\
\hline \multirow{2}{*}{$\begin{array}{l}\text { Hand } \\
\text { grip }\end{array}$} & Mean & 19.3 & 25 & \multirow{2}{*}{4.7} & \multirow{2}{*}{$\begin{array}{r}<0.001 \\
\mathrm{HS}\end{array}$} \\
\hline & $\pm \mathrm{SD}$ & 5.4 & 0 & & \\
\hline \multirow{2}{*}{ Pain } & Mean & 18.3 & 25 & \multirow{2}{*}{5.3} & \multirow{2}{*}{$\begin{array}{rl}<0.001 & \mathrm{HS}\end{array}$} \\
\hline & $\pm \mathrm{SD}$ & 5.7 & 0 & & \\
\hline \multirow{2}{*}{ ROM } & Mean & 19.0 & 25 & \multirow{2}{*}{$\begin{array}{r}5.0 \\
8\end{array}$} & \multirow{2}{*}{$\begin{array}{rl}<0.001 & \mathrm{HS}\end{array}$} \\
\hline & $\pm \mathrm{SD}$ & 5.3 & 0 & & \\
\hline \multirow{2}{*}{$\begin{array}{r}\text { Retur } \\
\mathrm{n} \text { to } \\
\text { work }\end{array}$} & Mean & 16.5 & 25 & \multirow{2}{*}{$\begin{array}{r}7.7 \\
6\end{array}$} & \multirow{2}{*}{$\begin{array}{r}<0.00 \\
\mathrm{H}\end{array}$} \\
\hline & $\pm \mathrm{SD}$ & 4.9 & 0 & & \\
\hline \multirow{2}{*}{ MMS } & Mean & 72.5 & 100 & \multirow{2}{*}{8.4} & \multirow{2}{*}{$\begin{array}{r}<0.001 \\
\mathrm{HS}\end{array}$} \\
\hline & $\pm \mathrm{SD}$ & 14.6 & 0 & & \\
\hline
\end{tabular}

Table 8: Comparison between operative side \& healthy side as regard Modified Mayo Wrist Score (MMWS score).

$\mathrm{T}$ : independent sample $\mathrm{T}$ test.

HS: p-value $<0.001$ is considered highly significant.

$\mathrm{X} 2$ : Chi-square test.

This table0shows highly statistical significant difference ( $p$-value $<0.001$ ) between studied groups as regard Modified Mayo Wrist Score (MMWS score) (hand grip, pain, ROM, return to work \& total MMS).

\section{DISCUSSION}

In our study we treated 20 patients, in a prospective study, having comminuted impacted distal radius fractures treated with dorsal plating and bone grafting. We will compare between our study and other studies published since 1998.

De Smet A, et al ${ }^{6}$ reported the results of 26 patients with impacted intra articular distal radius fractures treated with dorsal approach and internal fixation in a retrospective study with a mean age of 53 years. There were 10 females and 16 males. The average follow up was 39 months.

De Smet A, et al ${ }^{6}$ assisted R.O.M. in their study and it was $37^{\circ}$ flexion and $54^{\circ}$ extension. Pronation was $77^{\circ}$ and supination was $82^{\circ}$. Radial deviation was $15^{\circ}$ and ulnar deviation was $23^{\circ}$.

The operated hand's grip strength restored 81 percent of the healthy hand's strength. The score was 70 (out of 100) according to Modified Mayo Wrist Score.

$\mathrm{M}$. Herron et $\mathrm{al}^{7}$ reported the results of 30 patients with impacted intra articular distal radius fractures treated with dorsal approach and internal fixation in a retrospective study with a mean age of 42 years.
There were 11 women and 19 men. The average follow up was 11 months.

M. Herron et $\mathrm{al}^{7}$ assisted R.O.M. in their study and it was $46^{\circ}$ flexion and $50^{\circ}$ extension. Pronation was $81^{\circ}$ and supination was $76^{\circ}$. Radial deviation was $19^{\circ}$ and ulnar deviation was $32^{\circ}$. The operated hand's grip strength restored 78 percent of the healthy hand's strength

Hems TEJ et al ${ }^{8}$ reported the results of 34 patients with impacted intra articular distal radius fractures treated with dorsal approach and internal fixation in a retrospective study with a mean age of 39 years. There were 10 women and 14 men. The average follow up was 38 months.

Hems TEJ et al ${ }^{8}$ assisted R.O.M. in their study and it was $64^{\circ}$ flexion and $78^{\circ}$ extension. Pronation was $83^{\circ}$ and supination was $84^{\circ}$. The operated hand's grip strength restored 84 percent of the healthy hand's strength. The Modified Mayo Wrist Score in the final analysis was great in 12, nice in 4 and poor in 8 cases.

Simic et al ${ }^{9}$ reported the results of 51 patients with dorsally angulated distal radius fractures treated with dorsal approach and internal fixation in a retrospective study with a mean age of 59 years. The average follow up was 18 months.

Simic et al ${ }^{9}$ assisted R.O.M. in their study and it was $54^{\circ}$ flexion and $59^{\circ}$ extension. Pronation was $84^{\circ}$ and supination was $78^{\circ}$. The operated hand's grip strength restored 90 percent of the healthy hand's strength

Carter et al ${ }^{10}$ reported the results of 73 fractures and 71 patients with dorsally displaced unstable fractures of the distal radius. The patients averaged 45 years of age. Thirty-six were males and 35 were females. The average follow up was 18 months.

Carter et al ${ }^{10}$ assisted R.O.M. in their study and it was $52^{\circ}$ flexion and $58^{\circ}$ extension. Pronation was $82^{\circ}$ and supination was $82^{\circ}$. Radial deviation was $20^{\circ}$ and ulnar deviation was $31^{\circ}$. The operated hand's grip strength restored 87 percent of the healthy hand's strength. There was no tendon rupture, no nerve injury and no bone graft donor site morbidity.

lutsky et al ${ }^{11}$ reported the results of 15 patients with impacted intra-articular distal radius fractures. The average follow up was 37 months.

Lutsky et al ${ }^{11}$ assisted R.O.M. in their study and it was $53^{\circ}$ flexion and $70^{\circ}$ extension. Pronation was $76^{\circ}$ and supination was $80^{\circ}$. The operated hand's grip strength restored 87 percent of the healthy hand's strength

In our study we treated 20 patients, in a prospective study, having comminuted impacted distal radius fractures treated with dorsal plating and bone grafting.

Ages of our patients ranged between twenty two to fifty nine years with a mean age forty three years in our study that $65 \%$ of our patients were males, while $35 \%$ were females; in our study the follow up ranged between 6-12 months.

The mean range of motion at the end of our study was $58.2^{\circ}$ flexion and $53.3^{\circ}$ extension. Pronation was $76.1^{\circ}$ and supination was $82.1^{\circ}$. Radial deviation was $15.1^{\circ}$ and ulnar deviation was $25^{\circ}$.

The operated hand's grip strength restored 77.2 percent of the healthy hand's strength

The score was 72.5 (out of 100) according to Modified Mayo Wrist Score.

\author{
.
}


The overall complication rate in our study is $25 \%$. Post-operative complications occurred as followed, limited range of motion in $5 \%$ of patients because the patient didn't obey the instructions. Tendon irritation occurred in $10 \%$ of patients and tenosynovitis in $5 \%$ of patients. Tourniquet palsy occurred in 5\% of patients which resolve during follow up after 3 months.

We used low profile plates in 8 patients \& distal radius plates (T-L) in the rest. Results very good with low profile plates.

Strength of the study is:

One of the benefits of the dorsal approach is the joint surface that can be seen and reduced during surgery under clear vision.

Rate of tendon irritation and tenosynovitis very low with low profile plates.

With a secure reduction and bone graft, early vigorous mobilization is permitted which produces excellent and good functional outcomes.

Weak point of the study is:

Tendon irritation and tenosynovitis can occur with dorsal plating.

The recommendation is:

The dorsal plating when indicated in patient use a low profile plate and early mobilization of the joint.

\section{CONCLUSION}

In -articular distal radius fractures, Dorsal ORIF has its place. We continue to use dorsal approach for those impacted distal radius fractures with dorsal comminution. The dorsal approach and plating allows accurate reduction and maintenance with early mobilization, good function and an early return to work. We found that the dorsal approach allows anatomical and secured reduction with early mobilization, which produces excellent and good functional outcomes and early return to work.

\section{REFERENCES}

1. Kumar, S., Khan, A. N. \& Sonanis, S. V. Radiographic and functional evaluation of low profile dorsal versus volar plating for distal radius fractures. J. Orthop. 2016 ; 13, 376-82 .
2. RIKLI, D. A. \& REGAZZONI, P. The double plating technique for distal radius fractures. Tech. Hand Up. Extrem. Surg. 2000 ; 4, 107-14 .

3. Meena, S., Sharma, P., Sambharia, A. K. \& Dawar, A. Fractures of distal radius: an overview. J. Fam. Med. Prim. care 2014: 3, 325 .

4. Ross, M. \& Heiss-Dunlop, W. Volar angle stable plating for distal radius fractures. 2009.

5. Slutsky, D. J. Outcomes assessment in wrist surgery. J. Wrist Surg. 2013; 2, 1-4 .

6. De Smet, A. et al. Dorsal approach and internal fixation of impacted intra-articular distal radius fractures with $2.4 \mathrm{~mm}$ locking plates. Hand Surg. Rehabil. 2016 ;35, 203-9 .

7. Herron, M., Faraj, A. \& Craigen, M. A. C. Dorsal plating for displaced intra-articular fractures of the distal radius. Injury .2003;34, 497-502 .

8. Hems, T. E. J. \& Rooney, B. Open reduction and plate fixation of dorsally displaced fractures of the distal radius: surgical technique, clinical and radiological outcome. J. Hand Surg. 2010; (European Vol. 35, 56-60 .

9. Kamath, A. F., Zurakowski, D. \& Day, C. S. Lowprofile dorsal plating for dorsally angulated distal radius fractures: an outcomes study. J. Hand Surg. Am. 31, 2006 ;1061-7 .

10. Carter, P. R., Frederick, H. A. \& Laseter, G. F. Open reduction and internal fixation of unstable distal radius fractures with a low-profile plate: a multicenter study of 73 fractures. J. Hand Surg. Am. 23, 300-307 (1998).

11. Lutsky, K., McKeon, K., Goldfarb, C. \& Boyer, M. Dorsal fixation of intra-articular distal radius fractures using 2.4-mm locking plates. Tech. Hand Up. Extrem. Surg. 2009 ;13, 187-96 . 